the content of those schemes is by no means subject to the scrutiny one might expect. He raises some interesting issues that deserve exploration in a future issue of International Psychiatry, for example the pressure being brought to bear by insurance companies upon medically trained psychotherapists, who deliver expensive treatment in comparison with non-medical professionals. This has parallels with the 'hospital medical officer' saga in the United States over the past decade and raises the spectre of what some have called the practice of 'bottom line' medicine.

\section{Reference}

Adkoli, B. V. (2006) Migration of health workers: perspectives from Bangladesh, India, Nepal, Pakistan and Sri Lanka. Regional Health Forum, 10, 49-58.

\title{
Teaching and training in psychiatry and the need for a new generation of psychiatrists in Bangladesh: role of the Royal College of Psychiatrists
}

\author{
Mohammad S. I. Mullick \\ Professor of Child and Adolescent Psychiatry, Department of Psychiatry, Bangabandhu Sheikh Mujib Medical University, Dhaka, \\ Bangladesh,email mullick@bdonline.com
}

angladesh is a small, populous South Asian nation with poor literacy, limited resources and a lack of basic healthcare. Caring for people with psychiatric disorders in such a setting is challenging. The prevalence of psychiatric disorder in Bangladesh is similar to that in other countries, yet there is a severe shortage of well trained psychiatrists and a lack of even basic mental health services. To generate large numbers of well trained psychiatrists, Bangladesh must expand its high-quality psychiatric training and education at both the postgraduate and the undergraduate levels. To achieve these ambitious goals, Bangladesh needs help and assistance from regional and international institutions. The Royal College of Psychiatrists can play a role of critical psychiatric public health importance by helping Bangladesh locally train a new generation of psychiatrists who will care for the vast number of those with ailments of mind and soul.

\section{Bangladesh: basic facts}

Bangladesh is densely populated, having a total area of $147570 \mathrm{~km}^{2}$ and a population of 123.85 million. About $45 \%$ of that population are under 18 years of age and $72 \%$ live in rural areas. Islam is the major religion (practised by around $88 \%$ of the population), followed by Hinduism (11\%). Most Bangladeshis share a common language and sociocultural heritage. The economy, which in large part depends on agriculture, is perennially affected by flood (Asiatic Society of Bangladesh, 2003). The average per capita income is US $\$ 444$ and the economic growth rate is around 6\% per annum (Bangladesh Bureau of Statistics, 2004).

\section{Extent of mental health problems in Bangladesh}

The prevalence of mental health problems in Bangladesh has been variously estimated to be between $7 \%$ and $16 \%$ (Chowdhury et al, 1981; Mullick \& Goodman, 2005). It is estimated that over 11 million adults and 8 million children and adolescents are in need of mental health services. Yet these people face both a lack of adequately trained mental health professionals and the absence of a structured mental health service.

\section{Evolution of teaching and training in psychiatry}

After Bangladesh achieved independence from Pakistan in 1971, undergraduate psychiatry training was established, with new departments of psychiatry. In 1979 a postgraduate course was started at the Bangladesh College of Physicians and Surgeons (BCPS). A course offering a Diploma in Psychological Medicine (DPM) began in 1975 at the former Institute of Postgraduate Medicine and Research (IPGM\&R, now the Bangabandhu Sheikh Mujib Medical University, BSMMU). This course was replaced by an MPhil course in 1995. In 2001, an MD course in psychiatry started at the BSMMU. 
Courses and curricula for psychiatry training are regulated by the Bangladesh Medical and Dental Council (BMDC).

\section{Undergraduate training in psychiatry}

About 25 government and non-government medical colleges provide undergraduate training in psychiatry. The undergraduate MBBS course consists of 5 academic years plus 1 year of internship training. Undergraduate psychiatry courses are designed to provide basic psychiatric concepts (including behavioural science) and to train doctors in the diagnosis and management of common psychiatric problems in the community setting (Bangladesh Medical and Dental Council, 2004). Courses mainly consist of didactic lectures in psychiatry for a total of 20 hours during the clinical years. This is accompanied by a 4-week clinical rotation. Knowledge of psychiatric illnesses is not evaluated in the examinations.

\section{Postgraduate training in psychiatry}

The BCPS is the pioneer organisation in postgraduate medical education in Bangladesh. It currently offers a Fellowship (FCPS) in 40 disciplines and Membership (MCPS) in 15. Annually, 810 candidates are accepted into the Membership and 15-20 into the Fellowship Part I programmes in psychiatry.

A 3.5-year course leads to the Fellowship of the College of Physicians and Surgeons in Psychiatry (FCPS-Psych). It starts in July of each year. Candidates are required to have the MBBS or an equivalent medical qualification recognised by the BMDC and 1-year internship after passing the MBBS. Modelled on the MRCPsych, the FCPS-Psych comprises Part I, basic science, and Part II, clinical psychiatry. After completing Part I, candidates must complete 3 years of clinical training in psychiatry in a recognised institution and submit a dissertation before they become eligible for Part II.

The BSMMU is the premier postgraduate medical institution in Bangladesh and sets the gold standard for medical education and practice in the country (Bangabandhu Sheikh Mujib Medical University, 2005a). It offers a Master of Philosophy in Psychiatry (MPhil-Psych) course and Doctor of Medicine in Psychiatry (MD-Psych) programme, which both accept 20-22 candidates each year. Trainees receive training in general adult psychiatry as well as sub-specialties in psychiatry from qualified faculty members. MPhil-Psych is a 2-year course and MD-Psych is a 3-year course; they begin every January and July respectively. The basic requirements for acceptance into the MD programme are similar to those of the FCPS-Psych. Unlike the FCPS-Psych, however, it consists of three parts; Part II is a transitional one, involving both basic and clinical science (Bangabandhu Sheikh Mujib Medical University, 2005b).

MAG Osmani Medical College, Sylhet, is the only medical college with a postgraduate course in psychiatry: it has offered a Master of Philosophy in Psychiatry degree since 2003. On average 4-6 seats are available in each academic year. This MPhil-Psych has similar eligibility criteria to the FCPS and MD programmes. The course consists of three parts and is similar to the MD-Psych programme.

\section{Quality v. quantity}

The above courses and examinations set a high standard, which helps produce high-quality psychiatrists, but is also perceived as problematic in relation to overcoming the acute shortage of trained psychiatrists in the country. The shortage is likely due to lack of adequate exposure to psychiatry during undergraduate medical education and a lack of enthusiasm on the part of clinicians for psychiatry as a career.

\section{Current initiatives}

Current initiatives include increasing postgraduate training in psychiatry to 4 years and opening a child and adolescent psychiatry sub-specialty course at the BCPS. The National Institute of Mental Health (NIMH) in Dhaka is planning to offer an MD (Psychiatry) course from July 2007. The World Health Organization (WHO) envisions having at least one doctor in each rural health centre in psychiatry within the next 20 years.

\section{Future directions}

To meet the acute shortage of trained psychiatrists in Bangladesh, there is a need for both short- and long-term programmes. In the short term, postgraduate training programmes should be opened in all medical colleges. The quality of training and examination of the programmes should be supervised by either the regional public universities or, preferably, a central body, such as the BSMMU. Long-term plans should focus on reforming undergraduate medical education to incorporate expanded, structured training in psychiatry so that MBBS doctors are well prepared for the high standards of postgraduate training and examinations. In addition, psychiatry sub-specialty training programmes need to be started at the BSMMU and the NIMH. However, to accomplish these ambitious goals, Bangladesh needs assistance from regional and international agencies.

\section{Role of the Royal College of Psychiatrists}

The Royal College of Psychiatrists has played a key role in training Bangladeshi psychiatrists in the UK; many have since assumed leadership roles in improving psychiatric care in Bangladesh. However, to meet the acute shortage of well trained psychiatrists, Bangladesh now must train its own psychiatrists. The College Board of International Affairs, in particular the South Asia International Division, can play a vital role in improving the quality of psychiatric teaching and training in Bangladesh by facilitating collaboration among Fellows and Members in the South Asian Region. In particular, a short exchange training programme for mid-level psychiatrists would prepare them to assume leadership positions in developing new psychiatry training programmes. At its national meetings the College could recognise the substantial contribution its Members and Fellows make in developing psychiatry training programmes in Bangladesh.

The College could also send experts to give lectures and to deliver short courses, as well as unannounced examiners to the 
new postgraduate programmes, at random. The College could have delegates at the national annual meeting of psychiatrists. By recognising local training and degrees, the College could promote the development of a strong programme that would attract the best and the brightest to psychiatry. In addition, the College could consider waiving its own Part I examination for those with FCPS-Psych or MD-Psych degrees from Bangladesh, so that they could directly take the MRCPsych Part II examination. The College could also offer opportunities for sub-specialty training in psychiatry to psychiatrists with strong roots in Bangladesh, who would then lead the development of various domestic sub-specialty programmes.

\section{Conclusions}

Teaching and training in psychiatry in Bangladesh are in an advanced state of development. However, to meet the acute shortage of trained psychiatrists and to provide quality psychiatric care to large numbers of patients, Bangladesh must adopt short- and long-term strategies: expanding supervised high-quality postgraduate training to existing medical colleges; and incorporating expanded, structured psychiatric training at undergraduate level. To accomplish these ambitious goals with limited resources, it needs regional and international help. The Royal College of Psychiatrists played a historic role in training the first generations of Bangladeshi psychiatrists. The College can now play a pivotal role in improving psychiatric care in Bangladesh by helping to establish local training programmes for a new generation of psychiatrists, who will be well qualified and dedicated to improving the mental health of Bangladesh.

\section{References}

Asiatic Society of Bangladesh (2003) Banglapedia: National Encyclopaedia of Bangladesh. Asiatic Society of Bangladesh.

Bangabandhu Sheikh Mujib Medical University (2005a) Guide to Academic Programmes. BSMMU.

Bangabandhu Sheikh Mujib Medical University (2005b) Examination Manual. BSMMU.

Bangladesh Bureau of Statistics (2004) National Accounts Statistics (Provisional Estimates of GDP, 2003-04 and Final Estimates of GDP, 2002-03). Bangladesh Bureau of Statistics.

Bangladesh Medical and Dental Council (2004) Undergraduate Course Curriculum 2003-2004. BMDC.

Chowdhury, A. K. M. N., Alam, M. N. \& Ali, S. M. K. (1981) Dasherkandi project studies: demography, morbidity and mortality in a rural community of Bangladesh. Bangladesh Medical Research Council Bulletin, 7, 22-39.

Mullick, M. S. I. \& Goodman, R. (2005) The prevalence of psychiatric disorders among 5-10 year olds in rural, urban and slum areas in Bangladesh: an exploratory study. Social Psychiatry and Psychiatric Epidemiology, 40, 663-671.

\section{Teaching and training in psychiatry in India: potential benefits of links with the Royal College of Psychiatrists}

\section{P. Kulhara, ${ }^{1}$ MD FRCPsych FAMS, and A. Avasthi, ${ }^{2}$ MD MAMS}

'Professor and Head, ${ }^{2}$ Professor, Department of Psychiatry, Postgraduate Institute of Medical Education and Research, Chandigarh, 160012, India, email kulhara46_chd@dataone.in; param_kulhara@yahoo.co.in

\begin{abstract}
- ducation in modern medicine in India began in 1835 with the establishment of the Madras Medical College, in what is now Chennai. Initially the growth of new medical schools was slow but it gathered pace after independence in 1947. In the past decade or so, the growth in terms of the creation of new medical schools has been phenomenal.
\end{abstract}

\section{Undergraduate medical education}

The Medical Council of India (MCl) is a statutory body charged with the responsibility for regulating the establishment of medical schools in India. It lays down standards for undergraduate and postgraduate medical education and prescribes curricula for both. It has the power to accredit, recognise or de-recognise medical schools. According to a recent release from the $\mathrm{MCl}$, India has 233 recognised medical schools, to which 25374 students are admitted every year at the undergraduate level (see Table 1).

The undergraduate curriculum of the $\mathrm{MCl}$ gives meagre representation to psychiatry. Undergraduate medical students are exposed to psychiatry for only 15-20 hours by way of didactic lectures during the entire course of their medical education, which spans 4.5 years! The clerkship in psychiatry lasts only 2 weeks. During the 1-year compulsory internship, the psychiatric rotation is optional, and in any case that, too, lasts only 2 weeks. Furthermore, psychiatry has no prominence in the final examinations.

At organisational level, many medical schools even today do not have independent departments of psychiatry but rather psychiatry is catered for within the department of medicine; for those schools that do have a psychiatry department the staffing situation is generally poor. Moreover, training in psychiatry is perfunctory and tends to address the cognitive aspects rather than the psychomotor or affective aspects of mental disorder. 